\title{
A novel quick transendoscopic enteral tubing in mid-gut: technique and training with video
}

\author{
Chuyan Long ${ }^{1,2}$, Yan Yu ${ }^{1,3}$, Bota Cui ${ }^{1,2}$, Sabreen Abdul Rahman Jagessar ${ }^{1,2}$, Jie Zhang ${ }^{1}$, Guozhong ji ${ }^{1,2}$, \\ Guangming Huang ${ }^{1,2}$ and Faming Zhang ${ }^{1,2,4^{*}}$ (D)
}

\begin{abstract}
Background: This study aimed to evaluate the feasibility, safety, and value of a quick technique for transendoscopic enteral tubing (TET) through mid-gut.

Methods: A prospective interventional study was performed in a single center. A TET tube was inserted into mid-gut through the nasal orifice and fixed on the pylorus wall by one tiny titanium endoscopic clip under anesthesia. The feasibility, safety, success rate, and satisfaction with TET placement were evaluated for enteral nutrition or fecal microbiota transplantation.

Results: A total of 86 patients underwent mid-gut TET. The success rate of the TET procedure was $98.8 \%$ (85/86). Mean tubing time of the TET procedure was $4.2 \pm 1.9 \mathrm{~min}$. 10 cases of procedure was enough for training of general endoscopist to shorten the procedure time $(7.0 \mathrm{~min}$ vs $4.0 \mathrm{~min}, p<0.05) .97 .7 \%(84 / 86)$ of patients were satisfied with the TET placement. Procedure-related and tube-related adverse events were observed in $8.1 \%(7 / 86)$ and $7.0 \%$ (6/86) of patients respectively. There were no moderate to severe adverse events during tube extubation.
\end{abstract}

Conclusions: TET through mid-gut is a novel, convenient, reliable and safe procedure for mid-gut administration with a high degree of patient satisfaction.

Trial registration: This research was retrospectively registered with clinicaltrials.gov. Trial registration date: 29th November 2017. Trial registration number: NCT03335982.

Keywords: Transendoscopic enteral tubing, Mid-gut, Fecal microbiota transplantation, Enteral nutrition, Endoscopy, Nasal-jejunal tube

\section{Background}

In recent years, fecal microbiota transplantation (FMT) has gained appeal as a therapeutic option worldwide. Clinical studies have shown that FMT has a therapeutic role in clostridium difficile infection (CDI), inflammatory bowel diseases (IBD), refractory constipation, chronic diarrhea, liver diseases and metabolic syndrome [1-3].

Traditionally, microbiota can be administered through the upper-gut, the mid-gut, and the lower-gut pathways

\footnotetext{
* Correspondence: fzhang@njmu.edu.cn

${ }^{1}$ Medical Center for Digestive Diseases, the Second Affiliated Hospital of Nanjing Medical University, 121 Jiang Jia Yuan, Nanjing 210011, China

${ }^{2}$ Key Lab of Holistic Integrative Enterology, Nanjing Medical University, 121 Jiang Jia Yuan, Nanjing 210011, China

Full list of author information is available at the end of the article
}

$[4,5]$. FMT via colonoscopy is a classic approach, but in our previous study on ulcerativecolitis [4], those patients have difficulty to maintain the infused microbiota suspension for enough time through this way. Thus, we designed the colonic transendoscopic enteral tubing (TET) technology, which made whole-colon administration of treatment and repeat FMTs possible [5]. However, some patients are resistant to undergo bowel preparation for colonoscopy or some are not suitable for colonic delivering way. Therefore, mid-gut delivering way is an important option for those patients. In our previous researches on FMT for Crohn's disease [6, 7], patients and physician faced the similar problem that some patients need repeat FMT during hospitalization, and some may need enteral nutrition at the same time. 
In order to have a quicker and more convenient placement of mid-gut/nasal-jejunal TET tube than traditional methods, we designed a novel mid-gut TET technique without further confirmation for the location of tube in gut by X-ray or other medical devices after the endoscopic procedure. This study aimed to evaluate the feasibility, safety, and value of the mid-gut TET technique.

\section{Methods}

\section{Subjects}

This prospective interventional study was conducted at the Second Affiliated Hospital of Nanjing Medical University from September 2015 to September 2017. All patients were selected from our clinical trial without payment for the endoscopic devices and met the inclusion criteria, which were age 5-80 years, suitability for endoscopy, and consented to undergo TET placement for their diseases and conditions. Patients were excluded if they had severe diseases due to the risk of anesthesia. Informed consent was obtained from all adult subjects or parents in pediatric cases. The study was approved by the Institutional Review Board of the Second Affiliated Hospital of Nanjing Medical University.

\section{Preparations, procedures and assessment of TET}

Patients underwent the procedure under anesthesia. All patients need this mid-gut tube for frequent fecal microbiota transplantation and/or enteral nutrition support. Two to three $\mathrm{mL}$ of liquid paraffin oil (medical use level) was injected into TET tube and then the matched guide wire was inserted into the tube (FMT-DT-N-27/1350, FMT Medical, Nanjing, China). Then the tube was coated with paraffin oil by medical gauze and was inserted into the esophagus through nasal orifice under gastroscopic vision in oral cavity (Fig. 1a, b). The endoscope was then synchronously advanced to the stomach following the tube. The tube should be advanced into the distal duodenum with or without assistant of grasping forceps. As shown in Additional file 1: Video 1, the tube was fixed on the pylorus wall by one titanium clip (Fig. 1c) when the targeting circle ( $25 \mathrm{~cm}$ or $20 \mathrm{~cm}$ to the distal tip of the tube) for fixation was located at the pylorus. The endoscopy assistant must hold the tube for avoiding any migration while the endoscope is being slowly withdrawn. After the fixation, the guide-wire should be pulled out partially until the tip of the guide wire within the tube was pulled into the stomach (almost 25-30 cm), which could be confirmed under endoscopic vision. The endoscope should be inserted into duodenum for confirming no buckling changes of the soft tube within the intestinal cavity. The endoscope could be taken out of the body with the stable controlling of the tube from the assistant. The guide wire was required to be taken out of the tube slowly after the endoscope was out of mouth. Finally, the medical tape was used to fix the tube on

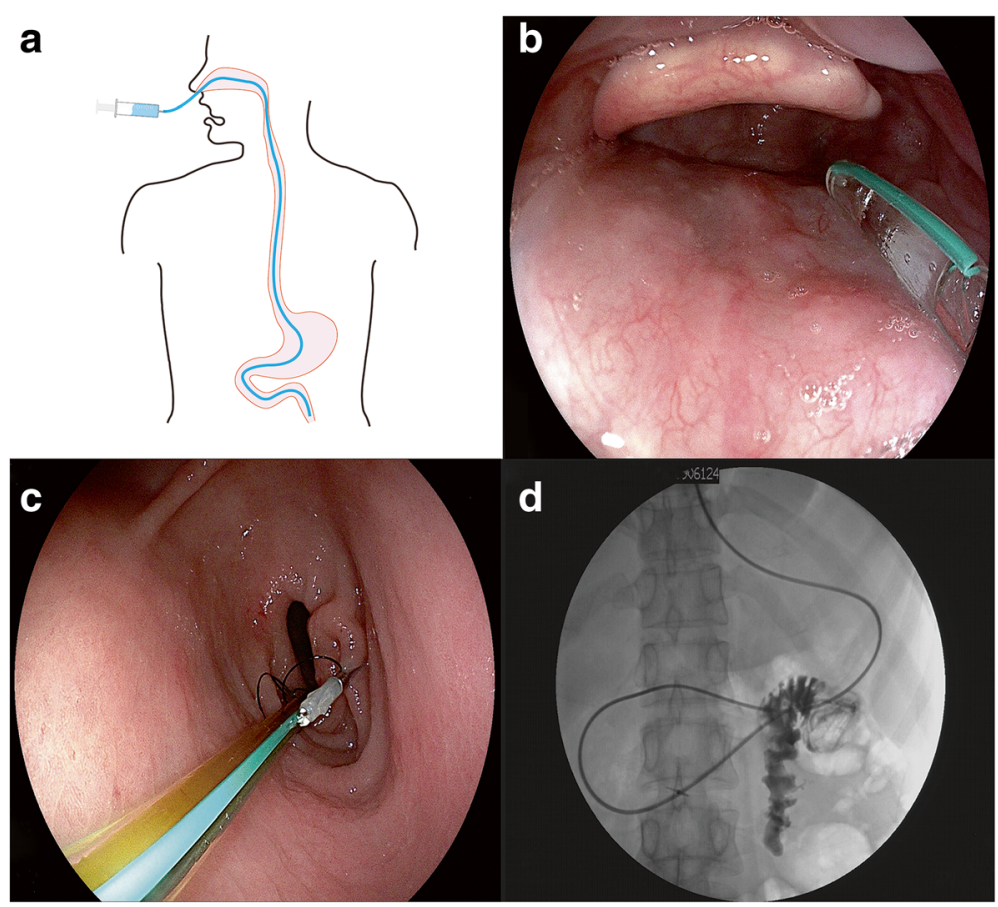

Fig. 1 Concept and procedure of administration through mid-gut tubing. a The concept of administration through mid-gut tubing; $\mathbf{b}$ The endoscopic view at mouth cavity when the soft tube tip from nasal cavity was inserted into hypopharynx close to esophagus; c One tiny endoscopic clip was used for fixation of the tube at gastric antrum before the guide wire within the tube was removed out; $\mathbf{d}$ The location of mid-gut tube could be confirmed by X-Ray and contrast agent, but is not necessary using this TET technique and device 
nose. According to our pilot study, the $100 \%$ (total 10 cases) of the distal tube could arrive at the target location (jejunum or distal duodenum) during the development of this device and technique. Therefore, there was no necessary to confirm the location of the distal tip of the tube under fluoroscopy (Fig. 1d). The endoscopic procedure was well-shown from the (Additional file 1: Video 1).

The primary aim of the study was rate of success on the tubing procedure. The secondary aim was rate of adverse events. The end point was 1 month after procedure. The duration of the procedure from nasal intubation to fixation of the titanium clip on the gastric wall was recorded as tubing time. Two endoscopists with different training experience performed the endoscopic procedures in this study. One endoscopist was at advanced level and another one was an endoscopist at general level who had finished about 300 case of endoscopy. In order to evaluate the difficulty of training for TET. The mean time of procedure were compared between and within the two endoscopists. After the fixation, further scanning of the stomach and esophagus or possible biopsy could be performed, but the time was not included. Procedure-related and tube-related adverse events, patient-reported discomfort and satisfaction on TET placement were also recorded. The grade of satisfaction was clarified as yes or no.

\section{Statistical analysis}

All statistical analyses were performed using SPSS software (version 19.0; SPSS Inc., Chicago, IL). Comparison of operating time and adverse event rate between two endoscopists was done with independent sample T-test and Chi square test, respectively. $P$ value $<0.05$ was considered to be statistically significant.

\section{Results}

As shown in Table 1, total 86 cases underwent transendoscopic enteral tubing in mid-gut. Forty-three males and 43 females aged 5 to 77 years (mean \pm SD, $37.1 \pm 17.8$ ). Of the 86 patients, the success rate of tube placement was $98.8 \%(85 / 86)$. There was only one failed attempt in one Crohn's disease patient with gastric-duodenal fistula and the reinsertion rate was $1.2 \%$. The mean procedure time (from beginning of tube inserting into the esophagus to the tube was fixed on the pylorus wall by one titanium clip) was $4.2 \pm 1.9 \mathrm{~min}$ (range, 1.53-11.25). The mean time of procedure was $3.3 \pm 0.9 \mathrm{~min}$ and $5.5 \pm 2.4 \mathrm{~min}$ for the advanced endoscopist and general endoscopist $(p=0.002)$, respectively. The mean time of the initial 10 patients for general endoscopist was longer than the time during the following 10 cases $(4.0 \pm 1.0$ vs $7.0 \pm 2.4 \mathrm{~min}, p=0.015) .20$ (23.4\%) patients were placed with tubes successfully without assistant from grasping forceps. Procedure-related adverse events included mild pharynx bleeding (1.2\%), limited epistaxis (4.6\%) and unplanned extubation during
Table 1 Characteristics of patients undergoing TET through mid-gut

\begin{tabular}{|c|c|}
\hline Item & Value \\
\hline Total number & 86 \\
\hline Age, mean $\pm S D$, years & $37.1 \pm 17.8$ \\
\hline Male, n (\%) & $43(50.0)$ \\
\hline \multicolumn{2}{|l|}{ Diseases } \\
\hline Inflammatory bowel disease, n (\%) & $36(41.9)$ \\
\hline Others, n (\%) & $50(58.1)$ \\
\hline TET success rate, $\mathrm{n}(\%)$ & 85 (98.8) \\
\hline Tubing time, mean $\pm S D$, min & $4.2 \pm 1.9$ \\
\hline Advanced endoscopist, mean $\pm S D$, min & $3.3 \pm 0.9$ \\
\hline General endoscopist, mean \pm SD, min & $5.5 \pm 2.4$ \\
\hline \multicolumn{2}{|l|}{ Aim of TET, n (\%) } \\
\hline FMT, n (\%) & $65(75.6)$ \\
\hline Mini-FMT, n (\%) & $27(31.4)$ \\
\hline Enteral nutrition, n (\%) & $20(23.3)$ \\
\hline Satisfaction survey for TET, n (\%) & $83(96.5)$ \\
\hline \multicolumn{2}{|l|}{ Adverse events of patients, n (\%) } \\
\hline \multicolumn{2}{|l|}{ Procedure-related } \\
\hline Mild pharynx bleeding, n (\%) & $1(1.2)$ \\
\hline Epistaxis, n (\%) & $4(4.6)$ \\
\hline Unplanned extubation, n (\%) & $2(2.3)$ \\
\hline \multicolumn{2}{|l|}{ Tube-related } \\
\hline Nausea, n (\%) & $1(1.2)$ \\
\hline Pharynx discomfort, n (\%) & $4(4.6)$ \\
\hline Rhinorrhoea, n (\%) & $1(1.2)$ \\
\hline
\end{tabular}

FMT fecal microbiota transplantation, TET transendoscopic enteral tubing

post anaesthetic recovery (2.3\%). Tube-related adverse events included moderate-severe pharynx discomfort (4.6\%), rhinorrhoea (1.2\%), and nausea (1.2\%). All patients were followed up for 1 month after discharged. Patientreported satisfactory rate was $96.5 \%$ (83/86). Only three (3.4\%) patients complained of obvious pharynx discomfort that they do not want to experience again.

\section{Discussion}

Traditionally, the nasojejunal tube can be placed blindly, with fluoroscopic or electromagnetic guidance, or more commonly, endoscopically. Blind placement of feeding tube beyond the pylorusis frequently unsuccessful and may lead to complications such as pneumothorax and pneumonia due to misplacement in the bronchus $[8,9]$. The success rate was reported 69 to $98 \%$ for electromagnetic (EM)-guided placement and 82 to $100 \%$ for endoscopic placement [10-16]. In our study the success rate of intubation was $98.8 \%$, superior to the Gerritsen's research [10] in which the 
successful placement of nasoenteral tubes was achieved in 3202 of 3789 (85\%) with EM-guided, 706 of 793 (89\%) with endoscope, and 413 of 446 (93\%) with fluoroscopic procedures. Especially for endoscopic placement, the rate of successful placement in this study (98.8\%) was much higher than Hirdes and Wildi's researches (124 of 143 (87\%) [17] and 132 of 157 (84\%) [18], respectively).

There was only one failed attempt in a patient with Crohn's disease who had gastric duodenal fistula, and finally, we reinserted the tube with fluoroscopy. The reinsertion rate was $1.2 \%$, which is much lower than reported [10] 21\% of EM-guidance (270 of 1279 ), $16 \%$ of endoscopy (64 of 394), and $26 \%$ of fluoroscopy (10 of 38).

Additionally, Gerritsen's [19] reported that only $36 \%$ of the patients with EM guidance and $71 \%$ of the patients with endoscopy avoided replacement procedure. The initial tube placement was successful in 58\% with EM guidance and 53\% with endoscopy $(P=0.71)$, much lower than in our research (98.8\%). Hirdes' research [17] consider that the more accurate post-pyloric tube placement can reduce the rate of repeat endoscopies.

The procedure time in our study was $4.2 \pm 1.9 \mathrm{~min}$, more time saving than the time from the research [10] on EM-guided placement (13.4 [12.9] minutes), which followed by endoscopy and fluoroscopy (14.9 [8.7] and 16.2 [23.6] minutes, respectively). Although EM-guided placement of nasojejunal feeding tube was used world widely for its convenience of beside placement by nurses [20], this electromagnetic device was not widely used in China. An important thing that should be highlighted: patients can benefit from the endoscopic procedure for possible lesion scanning in upper-gastrointestinal tract. Additionally, the cost of endoscopy and related anesthesia in China is cheap. This could be an important reason for us to have this TET, instead of choosing an expensive tube and special guidewire with electromagnetic detection or more X-ray confirmation.

Procedure-related and tube-related adverse events were recorded in 7 of $86(8.1 \%)$ and 6 of $86(7.0 \%)$ patients in our procedure, respectively. And there was no significant difference on rate of adverse events between two endoscopists $(p=0.94)$. The incidence rate of tube-related adverse events was far less than that with EM-guided, endoscopic, and fluoroscopic placement procedures [10]. Two patients removed the tube unconsciously post anesthesia which might be related to the discomfort of nasal or throat. Thus we suggest that patients should be gloved with restraint mitts during the time of post anaesthetic recovery. There were no tube fracture or leaking, dislocated or blockage in our study. All patients were followed-up within 1 month after discharged, and no more adverse events were observed.
Two endoscopists received basic TET skills training before this study. The mean procedure time of $3.3 \mathrm{~min}$ for the advanced endoscopist was shorter than $5.5 \mathrm{~min}$ for the general endoscopist. As number of cases increased, the time of procedure showed a decreasing tendency (Fig. 2a). This suggest that the experience of endoscopistis an influential factor that can affect the time of operation. This study indicated that 10 cases of procedure might be enough for training of general endoscopist to shorten the procedure time.

Inadvertent removal or displacement of the tube is common in conventional procedures [21, 22], and subsequently additional endoscopy or radiation would be necessary for reposition. In our study, the intubation procedure was carried out under direct vision, and the titanium clip was used to fix the tube and avoid migration.
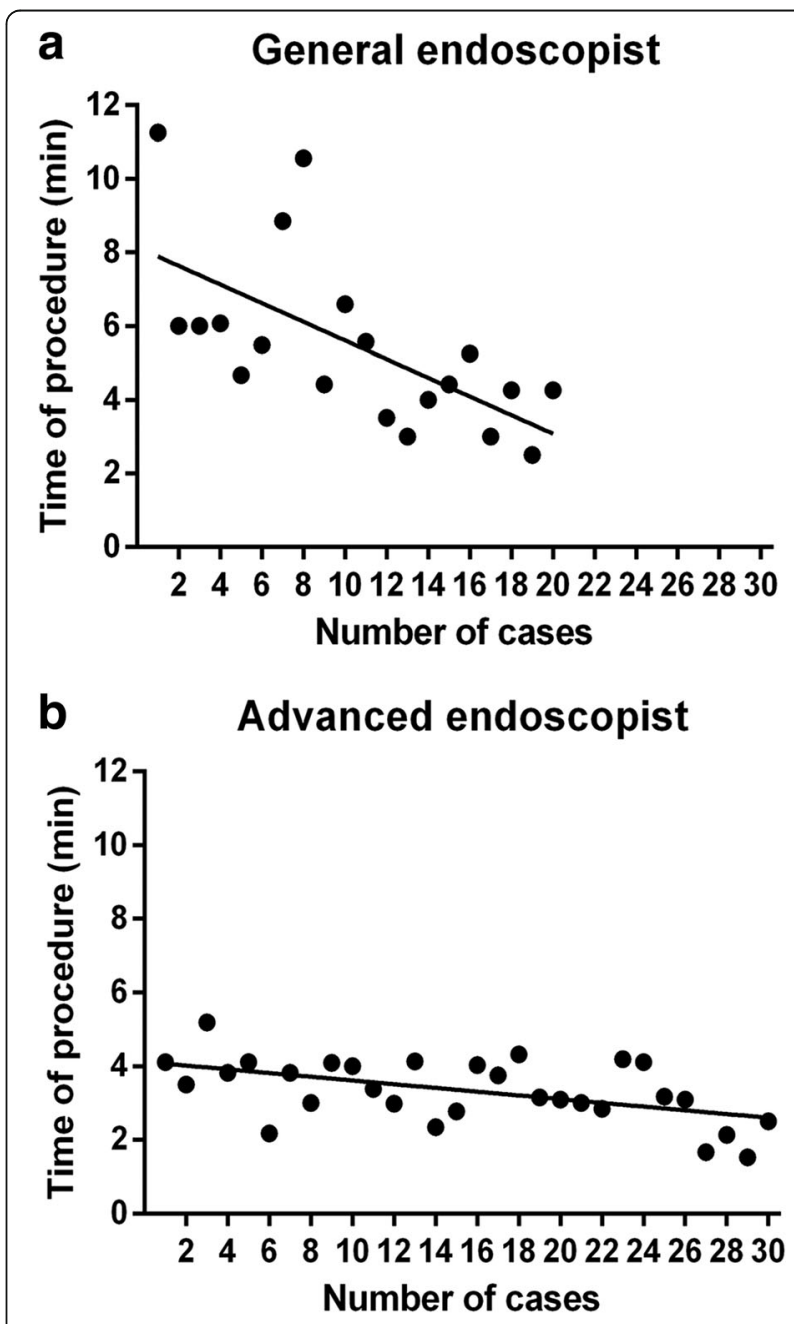

Fig. $\mathbf{2}$ The tendency of operating time in two endoscopists. a The time of procedure for the general endoscopist showed significant decreasingtendency during the training; $\mathbf{b}$ The time of procedure decreased slightly during the training in the advanced endoscopist 
Table 2 Comparison of different nasojejunal tube insertion methods

\begin{tabular}{|c|c|c|c|c|}
\hline & $\begin{array}{l}\text { Success } \\
\text { rate (\%) }\end{array}$ & $\begin{array}{l}\text { Tubing } \\
\text { time(min) }\end{array}$ & Advantages & Disadvantages \\
\hline TET & 98.8 & 4.2 & $\begin{array}{l}\text { Endoscopic view, time } \\
\text { saving, no need of switch } \\
\text { tube from mouth to nasal } \\
\text { orifice, no need of } \\
\text { confirmation by X-ray }\end{array}$ & Interventional endoscopy \\
\hline $\begin{array}{l}\text { Blind insertion } \\
{[24,25]}\end{array}$ & $17-68$ & - & Safe and less cost & $\begin{array}{l}\text { Time-consuming, low success } \\
\text { rate, need confirmation of the } \\
\text { location }\end{array}$ \\
\hline DSA $[10,26,27]$ & $84-96$ & $14.9-17.0$ & Safe and less cost & Time-consuming, X-ray exposure \\
\hline $\begin{array}{l}\text { EM-guided } \\
{[10,28,29]}\end{array}$ & $43-98$ & $6.2-20.0$ & $\begin{array}{l}\text { Operation by trained } \\
\text { nurses bedside, } \\
\text { no need of fasting }\end{array}$ & $\begin{array}{l}\text { Time consuming, the evidence for } \\
\text { altered upper Gl anatomy } \\
\text { after surgery is scarce }\end{array}$ \\
\hline $\begin{array}{l}\text { Traditional } \\
\text { endoscopic } \\
{[10,13,15,16,30]}\end{array}$ & $36-100$ & $6.6-28.0$ & $\begin{array}{l}\text { Under endoscopic } \\
\text { view }\end{array}$ & $\begin{array}{l}\text { Interventional endoscopy, time } \\
\text { consuming, tube location } \\
\text { changing, switching tube from } \\
\text { mouth to nasal orifice }\end{array}$ \\
\hline
\end{tabular}

TET transendoscopic enteral tubing, DSA digital subtraction angiography, EM electromagnetic

The present study demonstrated that this TET should be a convenient and economic way to undergo the frequent FMTs and enteral nutrition support. In this study, 65 (75.6\%) of patients underwent TET for FMT. 27 (31.4\%) patients underwent TET were for mini-FMT (a synthetic formula bacteria with specific bacterial species and stable formula). These data indicated that this mid-gut TET might be safe and useful for providing a new delivering way of microbiota transplantation.

There is no necessary to exchange the tube location from mouth to nasal orifice according to the designed concept of mid-gut TET. Based on our preliminary research during the earlier phase, we confirmed that there was no necessity to confirm the location of the tube by X-ray examination. If the doctor would like to confirm the location of the inserted tube at any time, successful suction of yellow-green bile, $\mathrm{pH}$ test for the suction fluid or X-ray could be used to have a defined answer [23]. The tube can be preserved for weeks, and it can be pulled out easily at any time when necessary. The attached line circle could be observed on the tube. Generally, the clip attached on line circle or not was probably related to the maintaining time of the tube.

Beyond the above discussion, we reviewed the reported indications and contraindications, advantages and disadvantages, success rates of different types of nasojejunal feeding tubes and related technology in Table 2. The distribution of indication for mid-gut TET includes: nasal-jejunal administration of medicine or enteral nutrition, mid-gut microbiota transplantation (including FMT or mini-FMT).

This study had limitations, including not large sample size, not randomized controlled study and no costeffective analysis. Meanwhile, recordings only from the two endoscopists were collected for analysis. The time of procedure was affected by difficulty of technique, and was also influenced by the individual differences. The comprehension and practical ability of endoscopist cannot be ignored. Further studies are necessary in the future for a more clear conclusion.

\section{Conclusions}

This novel TET technique is convenient, time-saving, and safe way for providing endoscopic mid-gut tubing for frequent microbiota transplantation and nutrition delivering. Moreover, this technique is easy for endoscopists learning and training practice.

\section{Additional file}

Additional file 1: The endoscopic procedure was well-shown from the video 1. (AVI $18990 \mathrm{~kb}$ )

\section{Abbreviations}

CDI: Clostridium difficile infection; DSA: Digital subtraction angiography; EMguided: Electromagnetic guided; FMT: Fecal microbiota transplantation; IBD: Inflammatory bowel diseases; TET: Transendoscopic enteral tubing

\section{Acknowledgments}

Not applicable.

\section{Funding}

This work was supported by Jiangsu Province 333 Talents Project (Zhang F), Jiangsu Medicine Innovation Team Project (Zhang F) and Jiangsu Department of Education for Science Foundation (Zhang F) supported the TET devices fee The hospitalization costs was supported by publically donated Intestine Initiative Foundation and National Science Foundation (81670495, 81600417). Partial financial support for researchers' salary and publication fee came from National Clinical Research Center for Digestive Diseases, Xi'an, China (2015BAl13B07). The funding bodies have no role in TET concept.

Availability of data and materials

The datasets used and/or analyzed during the current study are available from the corresponding author on reasonable request.

The CONSORT Statement

This manuscript reporting adheres to CONSORT guidelines. 


\section{Authors' contributions}

$\mathrm{CL}$ and $\mathrm{YY}$ equally contributed to this work; $F Z$ contributed to the design of the research; BC, JZ, GJ and GH performed the research; $C L$ and SAJ analyzed the data; and $\mathrm{CL}$ and $\mathrm{YY}$ drafted the manuscript. All authors read and approved the final manuscript.

\section{Ethics approval and consent to participate}

The study was approved by the Institutional Review Board of the Second Affiliated Hospital of Nanjing Medical University (2015KY042). Written informed consent was obtained from all adult subjects or parents in pediatric cases.

\section{Consent for publication}

Written informed consent for publication of clinical images and video was obtained from the patient.

\section{Competing interests}

Faming Zhang is the inventor of TET. Other authors declare that they have no competing interests.

\section{Publisher's Note}

Springer Nature remains neutral with regard to jurisdictional claims in published maps and institutional affiliations.

\section{Author details}

${ }^{1}$ Medical Center for Digestive Diseases, the Second Affiliated Hospital of Nanjing Medical University, 121 Jiang Jia Yuan, Nanjing 210011, China. ${ }^{2}$ Key Lab of Holistic Integrative Enterology, Nanjing Medical University, 121 Jiang Jia Yuan, Nanjing 210011, China. ${ }^{3}$ Changshu No.2 People's Hospital, 68 Hai Yu Nan road, Jiangsu 215500, China. ${ }^{4}$ National Clinical Research Center for Digestive Diseases, Xi'an, China.

Received: 31 October 2017 Accepted: 5 March 2018

Published online: 13 March 2018

\section{References}

1. Cammarota G, laniro G, Tilg H, Rajilic-Stojanovic M, Kump P, Satokari R, Sokol H, Arkkila P, Pintus C, Hart A, et al. European consensus conference on faecal microbiota transplantation in clinical practice. Gut. 2017;66(4):569-80.

2. Konig J, Siebenhaar A, Hogenauer C, Arkkila P, Nieuwdorp M, Noren T, Ponsioen CY, Rosien U, Rossen NG, Satokari R, et al. Consensus report: faecal microbiota transfer - clinical applications and procedures. Aliment Pharmacol Ther. 2017;45(2):222-39.

3. Surawicz CM, Brandt L, Binion DG, Ananthakrishnan AN, Curry SR, Gilligan PH, McFarland LV, Mellow M, Zuckerbraun BS. Guidelines for diagnosis, treatment, and prevention of Clostridium difficile infections. Am J Gastroenterol. 2013;108(4):478-98. quiz 499

4. Cui B, Li P, Xu L, Zhao Y, Wang H, Peng Z, Xu H, Xiang J, He Z, Zhang T, et al. Step-up fecal microbiota transplantation strategy: a pilot study for steroid-dependent ulcerative colitis. J Transl Med. 2015;13:298.

5. Peng Z, Xiang J, He Z, Zhang T, Xu L, Cui B, Li P, Huang G, Ji G, Nie Y, et al. Colonic transendoscopic enteral tubing: a novel way of transplanting fecal microbiota. Endosc Int Open. 2016;4(6):E610-3.

6. Cui B, Feng Q, Wang H, Wang M, Peng Z, Li P, Huang G, Liu Z, Wu P, Fan Z, et al. Fecal microbiota transplantation through mid-gut for refractory Crohn's disease: safety, feasibility, and efficacy trial results. J Gastroenterol Hepatol. 2015:30(1):51-8.

7. He Z, Li P, Zhu J, Cui B, Xu L, Xiang J, Zhang T, Long C, Huang G, Ji G, et al. Multiple fresh fecal microbiota transplants induces and maintains clinical remission in Crohn's disease complicated with inflammatory mass. Sci Rep. 2017;7(1):4753.

8. Halloran O, Grecu B, Sinha A. Methods and complications of nasoenteral intubation. JPEN J Parenter Enteral Nutr. 2011;35(1):61-6.

9. Blumenstein I, Shastri YM, Stein J. Gastroenteric tube feeding: techniques, problems and solutions. World J Gastroenterol. 2014;20(26):8505-24.

10. Gerritsen A, van der Poel MJ, de Rooij T, Molenaar IQ, Bergman JJ, Busch OR, Mathus-Vliegen EM, Besselink MG. Systematic review on bedside electromagnetic-guided, endoscopic, and fluoroscopic placement of nasoenteral feeding tubes. Gastrointest Endosc. 2015;81(4):836-47. e832
11. Mathus-Vliegen EM, Duflou A, Spanier MB, Fockens P. Nasoenteral feeding tube placement by nurses using an electromagnetic guidance system (with video). Gastrointest Endosc. 2010;71(4):728-36.

12. Gray R, Tynan C, Reed L, Hasse J, Kramlich M, Roberts S, Suneson J, Thompson J, Neylon J. Bedside electromagnetic-guided feeding tube placement: an improvement over traditional placement technique? Nutr Clin Pract. 2007;22(4):436-44.

13. Holzinger $U$, Brunner R, Miehsler W, Herkner H, Kitzberger R, Fuhrmann $V$, Metnitz PG, Kamolz LP, Madl C. Jejunal tube placement in critically ill patients: a prospective, randomized trial comparing the endoscopic technique with the electromagnetically visualized method. Crit Care Med. 2011;39(1):73-7.

14. Rivera R, Campana J, Hamilton C, Lopez R, Seidner D. Small bowel feeding tube placement using an electromagnetic tube placement device: accuracy of tip location. JPEN J Parenter Enteral Nutr. 2011;35(5):636-42.

15. Constable G, Pappachan J, Stroud MA. Endoscopic placement of the Bengmark tube. Endoscopy. 2003;35(11):980-1.

16. Qin H, Lu XY, Zhao Q, Li DM, Li PY, Liu M, Zhou Q, Zhu L, Pang HF, Zhao $\mathrm{HZ}$. Evaluation of a new method for placing nasojejunal feeding tubes. World J Gastroenterol. 2012;18(37):5295-9.

17. Hirdes MM, Monkelbaan JF, Haringman JJ, van Oijen MG, Siersema PD, Pullens HJ, Kesecioglu J, Vleggaar FP. Endoscopic clip-assisted feeding tube placement reduces repeat endoscopy rate: results from a randomized controlled trial. Am J Gastroenterol. 2012;107(8):1220-7.

18. Wildi SM, Gubler C, Vavricka SR, Fried M, Bauerfeind P. Transnasal endoscopy for the placement of nasoenteral feeding tubes: does the working length of the endoscope matter? Gastrointest Endosc. 2007;66(2):225-9.

19. Gerritsen A, Duflou A, Ramali M, Busch OR, Gouma DJ, van Gulik TM, Nieveen van Dijkum EJ, Mathus-Vliegen EM, Besselink MG. Electromagnetic-guided versus endoscopic placement of Nasojejunal feeding tubes after Pancreatoduodenectomy: a prospective pilot study. Pancreas. 2016;45(2):254-9.

20. Gerritsen A, de Rooij T, Dijkgraaf MG, Busch OR, Bergman JJ, Ubbink DT, van Duijvendijk P, Erkelens GW, Klos M, Kruyt PM, et al. Electromagnetic-guided bedside placement of Nasoenteral feeding tubes by nurses is non-inferior to endoscopic placement by gastroenterologists: a multicenter randomized controlled trial. Am J Gastroenterol. 2016:111(8):1123-32.

21. Hernandez-Socorro CR, Marin J, Ruiz-Santana S, Santana L, Manzano JL. Bedside sonographic-guided versus blind nasoenteric feeding tube placement in critically ill patients. Crit Care Med. 1996;24(10):1690-4.

22. Gilbert RT, Burns SM. Increasing the safety of blind gastric tube placement in pediatric patients: the design and testing of a procedure using a carbon dioxide detection device. J Pediatr Nurs. 2012;27(5):528-32.

23. Milsom SA, Sweeting JA, Sheahan H, Haemmerle E, Windsor JA. Nasoenteric tube placement: a review of methods to confirm tip location, global applicability and requirements. World J Surg. 2015;39(9):2243-52.

24. Mahajan R, Gupta R, Sharma A. Role of neck flexion in facilitating nasogastric tube insertion. Anesthesiology. 2005;103(2):446-7.

25. Bong $\mathrm{CL}$, Macachor JD, Hwang NC. Insertion of the nasogastric tube made easy. Anesthesiology. 2004;101(1):266.

26. de Aguilar-Nascimento JE, Kudsk KA. Clinical costs of feeding tube placement. JPEN J Parenter Enteral Nutr. 2007;31(4):269-73.

27. Welpe P, Frutiger A, Vanek P, Kleger GR. Jejunal feeding tubes can be efficiently and independently placed by intensive care unit teams. JPEN J Parenter Enteral Nutr. 2010;34(2):121-4

28. Boyer N, McCarthy MS, Mount CA. Analysis of an electromagnetic tube placement device versus a self-advancing nasal jejunal device for postpyloric feeding tube placement. J Hosp Med. 2014;9(1):23-8.

29. Powers J, Luebbehusen M, Spitzer T, Coddington A, Beeson T, Brown J, Jones $\mathrm{D}$. Verification of an electromagnetic placement device compared with abdominal radiograph to predict accuracy of feeding tube placement. JPEN J Parenter Enteral Nutr. 2011;35(4):535-9.

30. Holzinger U, Kitzberger R, Bojic A, Wewalka M, Miehsler W, Staudinger T, Madl C. Comparison of a new unguided self-advancing jejunal tube with the endoscopic guided technique: a prospective, randomized study. Intensive Care Med. 2009:35(9):1614-8. 